\title{
PSYCHIATRY AND THE PROBLEM OF CRIMINAL RESPONSIBILITY*
}

\section{Robert Waelder†}

\section{The Present State of Affairs}

Our present penal system provides for punishment of lawbreakers, but defines a category of offenders as exempt from punishment: those who are irresponsible. The question of responsibility is decided, in each case, according to the M'Naghten rule $;^{1}$ in practice, it is in the hands of the psychiatric expert who has to answer the M'Naghten questions.

The rationale for this system is simple. It is the purpose of the law to define "minimum standards of behavior which men can disregard only at their peril" (Oliver Wendell Holmes). The penal law is therefore the extreme example of the principle of regulating human behavior by means of reward and punishment-a principle which permeates all spheres of life. We educate our children, by and large, by rewarding certain types of behavior with approval and love, and by

* This article has grown out of work done in the Committee on Forensic Psychiatry of the Group for the Advancement of Psychiatry (G.A.P.) to which the author has served as a consultant for some time. The ideas of the article are the outgrowth of the give-and-take of the discussions in the Committee, and it no longer is possible for me to disentangle my own part from contributions by the members of the Committee (Dr. Frank C. Curran, Dr. Lawrence Z. Freedman, Dr. Manfred O. Guttmacher, Dr. Philip Q. Roche) and its juridical consultants during the period in question (Professors George Dession, Arthur R. Pearce, Louis Schwartz and Herbert Wechsler) and former members and others who have contributed to the discussions. While thus recognizing my obligations, I hasten to add that the responsibility for opinion is mine only.

$\dagger$ Ph. D., U. of Vienna (Austria), 1922. Graduate, Vienna Psychoanalytic Institute, 1924. Editor, Imago (a periodical devoted to the applications of psychoanalysis to the biological and social sciences), 1932-39. Training and supervising analyst at the Institutes for the professional training for psychoanalysts in Philadelphia. Member, Editorial Board, Journal of the American Psychoanalytic Ass'n.

1. The so-called M'Naghten rule says: (1) To establish a defense on the ground of insanity it must be clearly proved that at the time of committing the act the party accused was laboring under such a defect of reason from disease of the mind as not to know the nature and quality of the act he was doing or if he did know it that he did not know he was doing what was wrong. (2) If a person is laboring under partial delusions only and is not in other respects insane and commits an offense in consequence thereof he must be considered in the same situation as to responsibility as if the act in respect to which the delusions exist were real. M'Naghten's Case, 10 Cl. \& Fin. 200, 8 Eng. Rep. 718 (1843). 
punishing others with some kind of sanction. Students in schools, from the elementary to the postgraduate level, have to live up to the standards of the institutions or else they will be punished by low grades or by non-promotion. Employees have to live up to the requirements of their jobs, or they will not be promoted or may lose their jobs altogether. Business men must meet the requirements of the market and must foresee its fluctuations or face financial loss. Professional people must live up to expectations or lose their clientele. Our life is regulated by this principle from the beginning to the end. There is no reason to doubt that the method, on the whole, is successful and delivers the goods.

But unless it is implemented in the case of any actual infringement of the law, the threat of punishment will soon lose its deterring power. While this principle is accepted in general, we feel that there are certain types of cases in which the failure to punish would not diminish the deterring potential of the threat of punishment for others. This is the case with people who are either unable to grasp or unable to anticipate the threatened punishment and who therefore are not influenced by this threat; or those whose motivation is of such a nature that anticipated punishment makes no difference in their behavior. Punishment, in such instances, is not useful as a means of dissuading the offender from repeating his unlawful act, nor is it necessary for general determent since the man on the street senses well enough that these people are different from himself and cannot be measured by the same yardstick. Punishment of offenders in this group is therefore unnecessary from the point of view of upholding the deterring function of the law. Moreover, it seems to us to be morally wrong because we feel that offenders of this group are not "guilty" in the usual sense. Since anticipation of legal consequences formed no part of their motivation, we feel that they have not had an adequate chance of guiding their actions according to the standards of the community.

Once the principle of singling out the non-deterrable group had been recognized, there arose the question of defining simple, easily applicable criteria to determine whether or not a particular offender belonged to this group. The M'Naghten rule offers such criteria, and, whatever else may be felt about it in the light of the experience of a century, it must be admitted that the rule is at least simple. The M'Naghten rule reflects what may be called a minimalistic policy regarding the members of this class of irresponsibles. When strictly applied, it exempts from punishment the feeble-minded and organic and functional psychotics with impaired perception or blurred consciousness; it exempts some but by no means all paranoiacs and paranoid 
schizophrenics. ${ }^{2}$ It leaves many psychotics and all psychopaths and cases of so-called primary behavior disorder within the reach of punishment.

For some time attempts have been made to enlarge the class of irresponsibles by adding a criterion of volistic impairment ("irresistible impulse") to the perceptual and conceptual criteria of the M'Naghten rule. Also, there have been attempts at re-interpreting the M'Naghten rule in such a way that it could be applied to cases of "irresistible impulse"-through the reasoning that "knowledge" implies the possibility of acting upon it and, where such possibility is lacking, memory rather than knowledge is involved.

\section{Psychiatric Discontent With the Present State of Affairs}

These modern trends seem to indicate dissatisfaction with the operation of the M'Naghten rule. Many psychiatrists and lawyers do not approve of the minimalistic definition of irresponsibility and wish to enlarge the class of offenders who can use the defense of insanity because there are many more undeterrable people than are caught by the M'Naghten test.

In addition to such criticism raised by psychiatrists and lawyers alike, there are specific factors that make for psychiatric discontent:

(1) Many psychiatrists seem to resent a situation in which they are compelled to speak a language not their own, which they either feel to be prescientific or which they, rightly or wrongly, suspect to be loaded with metaphysical implications not easily perceived.

Clinical psychiatrists are used to thinking in terms of syndromes (such as delusions, hallucinations, depressions, elations, etc.) or of

2. Some of the psychiatric terms used in this article need an approximate definition. Schizophrenia does not mean what the word has come to mean in newspaper editorials: an inner conflict, a dilemma. A schizophrenic person has broken with reality over a considerable area of life; i.e., broken both in the sense of a major impairment of perception or judgment of reality, inaccessible to the corrective influence of experience, and of emotional estrangement from people, sometimes to the degree of complete withdrawal and inaccessibility. Angular mannerisms of bodily movement or rigid bodily immobility are often part of it. The illness proceeds usually in episodes after each of which there may be a far-going, though not quite complete, restoration of the preceding state. The more schizophrenic episodes a patient has incurred, the greater is the likelihood of an outcome in intellectual deterioration (demence).

Manic-depressive psychosis is characterized by either severe melancholic depressions with suicidal trends or by excessive elations, or both. The illness usually moves in periods and after each period there is a practically complete restoration of the pre-psychotic personality.

Psychopathy is not a uniformly used term. Mostly, it refers to impulse-ridden personalities, to people whose actions are determined by short-term goals of gaining pleasure or avoiding frustration or anxiety, and who are incapable of modifying their behavior by long-term anticipations. 
disease entities (such as schizophrenia, manic-depressive psychosis, etc.). Those who have absorbed psychoanalytic concepts are also accustomed to think in dynamic and genetic terms such as inner conflicts and their attempted solutions, and the conditioning by childhood experience. But in neither case do the terms "right" or "wrong," essential in applying the M'Naghten rule, or the concept of "knowing" the difference between right and wrong, carry a precise psychological or psychiatric meaning. It would be different if these terms merely referred to what is, and what is not, prohibited by law; in that case, the second M'Naghten question would come down to this question: did the offender know that his action was unlawful? But this is not the meaning of the crucial question. ${ }^{3}$ As a result, the psychiatrist is prevented from using the language in which he has been trained to organize his thoughts and in which the meaning, the fringes of meaning and the implications of each term are familiar to him. Instead, he is forced to testify in a language not his own, and he cannot be sure of the implications which his words may seem to carry to the judge or to the jury.

Jurists sometimes do not seem to realize that this is a real problem. Since the words of the M'Naghten rule do not seem problematic to them, they are inclined to conclude that the reluctant psychiatrists are slow in fulfilling their civic duties or are actually trying to obstruct the administration of the law because they disapprove of it. Such obstruction may occur, but it is not the object of the considerable number of psychiatrists who have a sense of futility and even of humiliation comparable to what a physicist might feel were he required to testify in matters of radioactivity but prevented from using the vocabulary of his science and forced to dress his ideas in the language of Aristotle; or what a surgeon might feel were he asked to testify on the consequences of an accident in the language of Galen.

3. In the case of the defendant Schmidt who had confessed homicide and claimed that he had been ordered to kill by the voice of God, the New York Court of Appeal held that, had this been the case, the defendant would not have known that what he did was wrong and, hence, would not have been responsible. People v. Schmidt, 216 N.Y. 324, 110 N.E. 945 (1915).

Once knowledge of what is wrong is not simply interpreted as knowledge of the fact that an act is forbidden by law, we are headed for difficulties. The killer who received the order to kill by a voice which he thought was the voice of God was ruled irresponsible. Another offender may fancy himself under such divine order but without acoustic sensations; he may, or may not, be considered irresponsible. But let us go one step further from the concrete to the abstract: a man who felt he received the order te kill by a less personalized power and who acted on the command of his conscience, persuaded by what he thinks is his duty toward his ideology, his nation, his party, etc., is certainly considered responsible. Yet, from a psychological point of view, the difference between these cases seems hardly fundamental. 
(2) Somewhat related to this issue of semantic ambiguity and coercion in matters of semantics is a feeling among psychiatrists that the words of their testimony carry implications for the judge and the jury which these words do not have for them, and that slight differences in the wording of their testimony, equally justifiable from a psychiatric point of view, may make all the difference in the world for the jury, and may provide either the prosecution or the defense with effective arguments for their causes. The psychiatrist feels maneuvered into a pivotal position. While remaining entirely within the limits of correctly discharging his professional responsibilities, he has actually leeway to decide, in fact though not in theory, the fate of the defendant. Such a situation can be a source of serious inner conflicts.

(3) Finally, there is a third factor operative in psychiatric discontent; it may seem less valid than the former ones. Scientists and professional people are often tempted to apply their particular approach to problems beyond the area in which the approach has developed, and such extensions may, or may not, be fruitful. In this sense, some psychiatrists feel that their professional way of handling things may yet be the answer to many social ills.

In his normal professional life, the psychiatrist meets people as patients whom he is supposed to treat. Thus, when called upon to see a criminal, he may approach him in the same spirit, $i . e$., as a patient to be given medical treatment. It may happen that the psychiatrist is not sufficiently aware of the fact that the law means to treat the offender not only with a view to his salvation but also with the view of upholding minimum standards of behavior in the society at large. Moreover, a very small but articulate number of psychiatrists have claimed that the threat of punishment does not deter at all-a radical contention in view of everybody's daily experience in office and shop, in the parlor and on the market, on the playfields and on the public highways.

Actually, there is as yet not much to substantiate even the claim that psychiatric treatment could rehabilitate the individual offender in a significant number of cases. Penetrating treatment with a view to a re-orientation of the personality-psychoanalysis-is time-consuming and takes a sizeable part of the total working life of a highly skilled practitioner; nonetheless, the desired therapeutic result cannot be guaranteed even for psychoneurosis, the subject par excellence for psychoanalytic treatment, and the outlook for delinquency is certainly less bright. Whether short term psychotherapy-the only treatment that could at this point be made available on a relatively large scale-can "cure" the more severe forms of delinquency remains to be seen. 
Those psychiatrists who would base their claims on the preventive rather than the therapeutic potentialities of psychiatry encounter another difficulty. It is quite true that psychiatry could well pick out individuals who might become delinquent. But psychiatry could hardly say: this person will certainly commit, say, homicide. It may say that he might do so, i. e., that he has a 100 times greater chance of doing so than the next person. But so have a number of other, equally tempted and equally labile, people who never actually commit a crime. For one dangerous psychopath who eventually becomes homicidal, there are scores of psychopaths, apparently equally dangerous, who do not make the fatal step from temptation to action. Our system would not countenance the permanent imprisonment of fifty people who have so far broken no law because we know statistically that one of them will commit homicide if given the opportunity.

\section{Two Possible Modifications of the M'Naghten Rule}

There are, above all, two modifications of, or additions to, the M'Naghten rule which have been advocated and which are practiced in some legal systems.

(1) The irresistible impulse.-It has been suggested that the question as to the offender's knowledge of right and wrong should be supplemented by a question as to his ability to act upon his insight. In this way, allowance may be made for an "irresistible impulse."

Whatever advantages this suggestion may hold from the point of view of our sense of justice, it is unlikely to improve the position of the psychiatrist. The concept of an irresistible impulse is well-defined only in a central area where certain impulses are irresistible to all people. We may say, for example, that the need to sleep becomes irresistible after a certain time. Some people may be able to stay awake longer than others but a point is reached after some hours when the need to sleep cannot be conquered by anyone. The same applies to many other physical needs such as, for example, the need to urinate.

But when we enter the territory of impulses that are resisted by some and not by others, and we should decide whether an urge that Tom could safely check was unconquerable for Dick, we are on shaky ground. There are no criteria for this decision. ${ }^{4}$

4. In the course of a psychoanalytic treatment, an analyst sometimes is confronted with the problem of finding out whether an impulse is, or is not, irresistible. $E . g$, an agoraphobic who has long since ceased going out alone may have progressed in his treatment to a point where the analyst may wonder whether the patient's anxiety may not have abated to a degree so as to be tolerable. But there is no way of deciding this question unless the patient puts his anxiety to a test, i.e., actually ventures to go out alone so that it can be determined by trial and error whether his anxiety is still beyond tolerance. 
(2) The question of insanity.-Another possibility is to ask the psychiatrist whether the offender was suffering from a mental disease, and if so, whether or how his act was related to this condition.

However, this method also does not remove the difficulty. The concept of mental disease is well-defined and beyond controversial interpretation only in a central core of the concept, $i$. e., with regard to such conditions in which the sense of reality is crudely impaired, and inaccessible to the corrective influence of experience-for example, when people are confused or disoriented or suffer from hallucinations or delusions. That is the case in organic psychoses, in schizophrenia, in manic-depressive psychosis. Their characterization as diseases of the mind is not open to reasonable doubt.

But outside of this inner core, there is a vast fringe area of conditions which may, or may not, be considered to be diseases of the mind. Are p̌sychopathies, psychoneuroses (like kleptomania) or perversions (like exhibitionism) diseases of the mind? The definition of the term becomes arbitrary, and the above questions will be answered differently by different psychiatrists. Whether or not a psychiatrist is willing to classify any one of these conditions as diseases of the mind depends more on his philosophy than on any factual question that can be settled by observation and reasoning.

One could conceive of a system in which the psychiatrist is asked only such questions about which it is clearly within his professional competence to testify. This would be the case if he were asked about the offender's mental condition, not in general terms but in concrete terms of specified diagnostic entities. Is this offender a moron? Does he suffer from an organic psychosis? Is he a schizophrenic, a manicdepressive? Is he a "borderline" schizoid, a psychopath, a psychoneurotic, etc.? (Allowance would have to be made for a considerable number of categories.) And if so, to what extent is his act related to this condition?

Psychiatrists can answer these questions without misgivings. While there is no complete standardization of terminology among different schools of psychiatry, the establishment of a uniform terminology is not beyond possibility. But in such a system the answer of the psychiatrist would not suggest that a person was, or was not, responsible. It would (and should) be up to the psychiatrically informed legislator to decide which of these psychiatric categories should, and which should not, substantiate the defense of insanity. 


\section{The Center of the Difficulty}

This carries us to the core of the problem. The seemingly factual question of whether or not a person is (or was) mentally ill, or was acting under an irresistible impulse, covers a question of morality and public policy: whether he should be punished or subjected to some other disposition or be allowed to leave the courtroom a free man. It would not be too difficult to agree that the "normal" offender (e.g., the racketeer who miscalculated his risks) should face the penalty and that the manifestly insane should be committed to a mental institution. ${ }^{5}$ But what should be done with a large group of offenders who do not fit into either of these two extreme categories? How should we deal with psychopaths, borderline schizoids, or perverts? They have not made calculations of gain and risk like the racketeer; nor are they insane. They do not seem to be deterrable, but the man on the street does not feel them to be too different from himself and would look askance at their remaining unpunished.

The exhibitionist is a case in point. He has been in and out of jail for the better part of his life. Or perhaps he has not been apprehended as yet, but jeopardizes a respectable position in life and puts himself at the mercy of a stranger each time he exhibits himself. He has made good resolutions many times over and tried to fight against his temptations; time and again the flesh has proved weak. As a matter of experience one can call him undeterrable. It may well be that he would not exhibit himself were the policeman present at the right moment, but short of this he cannot be deterred by the threat of any punishment that morally can be applied and that will not be so brutal as to be worse than the offense it is meant to forestall. He is certainly not psychotic. The man on the street does not feel this type of offender to be sufficiently different from himself so that he can let him off without danger to his own morale-except after such an offender has been in trouble many times and has continued his perverse practices nonetheless.

Behind the apparent problem of defining criteria of criminal responsibility, there is the real problem of how to deal with the large group of offenders who do not fit into the marginal categories of "normality" and insanity-the group of psychopathies, primary behavior disorders and perversions. This is not a factual question, to be decided on the basis of expert testimony-e. $g$., whether or not the offender "knew" that what he did was "wrong," or whether or not his particular mental make-up should be properly termed a "disease of the mind,"

5. At present hallucinating psychotics may pass the M'Naghten test. 
or whether or not his impulse was "irresistible." Rather it is a question of legal policy to be decided by all of us as citizens, guided by prevailing standards of morality and by the social interests at stake. In trying to arrive at a policy in this matter, we have to take advice from experts-psychiatrists among them-as to the facts and as to the probable consequences of any policy on which we may embark. But the decision-and the responsibility-is ours as citizens. We cannot pass it on to the expert witness by asking him questions which appear to be questions of fact but are actually questions of what we ought to do.

\section{Possibilities of a Frest Approach}

Whenever the existing line of approach does not seem to lead to a satisfactory solution, a fresh beginning may be tried. I am a layman in jurisprudence-a shortcoming which must necessarily detract from the validity of my reasoning but may hold some compensation. I may venture into speculation about a desirable solution without regard for the realities of existing law, leaving it to lawyers to decide how much, if any, of such speculation can be used either within the existing legal framework or after such changes of the statutory law as reasonably can be attempted.

When we try to make a fresh approach to the problem of dealing with crime and to the role which psychiatry, the science of human maladjustment, could fulfil in a reformed system, we may well start by remembering the various purposes, sometimes contradictory with one another, which society pursues in dealing with offenders. The penal law and its administration seems to serve these purposes: (1) retribution, (2) individual prevention, (3) rehabilitation of the offender, (4) general deterrence.

Whenever somebody has broken a law which we uphold we seem to feel that retribution is his just desert. It is as though his offense had disturbed an equilibrium which can be restored only by his punishment. This demand, operative to some extent in all of us, that the sinner should be punished is more than an expression of the utilitarian principle of enforcing minimum standards of conduct; we seem to feel that it is not "right" for the offender to "get away with it"-though we may differ widely with regard to the harshness of retribution which some think is necessary or the leniency which others are confident is adequate.

Many people have taken a stand against the principle of retribution altogether and have denounced it as a relic of barbarian times. This fact may suggest that the request for punishment of the offender is not a universal need of the human mind. But it turns out upon 
closer examination that the opponents of retribution are actually not what they claim to be; they are not free of the wish that "evil" men should be punished but have merely changed the object of their retributive strivings. While they do not feel that the criminal is guilty and should be punished, they are yet in a fully retributive mood towards "society," "the ruling class," the judges, etc. They are no exceptions from the rule that punishment appears to us as a postulate of justice; they have merely turned the tables and substituted the "respectable" citizen for the lawbreaker in their penitentiary.

Why we should all feel the need of retribution for the violation of a moral principle which we uphold is an important psychological problem which is beyond the scope of this study. For our purpose, it is sufficient to realize that this need, for whatever reason, actually exists.

In view of this sentiment, the complete elimination of the concept of retribution from the legal system may not be without danger. It would tend to dissociate the law entirely from moral sentiment. If the law no longer must conform, by and large, to moral standards, utilitarianism or expediency becomes its only guide. The emancipation from traditional moral sentiments, begun at first for humanitarian purposes, may eventually have consequences not so humanitarian. Once everything can be done that appears to be socially useful, $i$. $e$, that is so considered by those who have authority to define social usefulness, a course has been charted that may well end in despotism. Liberal positivism, in its humanitarian distaste for the harsher aspects of traditional morality, may, by undermining the authority of traditional morality, become the pathbreaker of more ruthless successors. The humanitarian goal with which I am in full sympathy seems to me to be better served by the progressive mitigation of the severity of retribution rather than by an attempt to eliminate the retributive aspect altogether.

The other goals of penal regulations, viz., individual prevention, rehabilitation and general deterrence, are generally recognized. These four goals, however, are often in conflict with one another.

\section{Retribution v. Individual Prevention}

The requirements of retribution and of individual prevention interfere with each other whenever retribution seems to require a degree of punishment which may drive a delinquent further along the road of crime ("prisons are the universities of crime") or, vice versa, whenever individual prevention would require a form or a degree of punishment which does not seem warranted in terms of retribution. 


\section{Retribution $v$. Rehabilitation}

These goals interfere with each other whenever retribution is such as to make rehabilitation impossible (e.g., capital punishment) or more difficult (deteriorating influence of long prison sentences) and rehabilitation could be advanced only at a sacrifice in terms of retribution.

\section{Retribution v. General Deterrence}

Retribution and general deterrence interfere with each other whenever retribution does not operate as a deterrent but as a bait. This may be the case, for example, of homeless destitutes to whom prison sentences may be actually attractive. Any kind of punishment, including capital punishment, may be attractive to masochistic perverts or to people suffering from an unconscious sense of guilt; their number may be small but they exist. There are also those who wish to be martyrized to serve their cause. No doubt the punishment meted out by the Romans against the Christians was not much of a deterrent. And finally, perhaps most important, there may be the general brutalizing influence of retribution among the people at large.

\section{Individual Prevention v. Rehabilitation}

These goals interfere with each other whenever individual prevention would require lengthy, or permanent, custody of the criminal while rehabilitation could be tried only if society was willing to take a chance with him.

\section{Individual Prevention v. General Deterrence}

These goals interfere with each other in those cases in which individual prevention could be achieved with little or no punishment while general deterrence seems to require it. Beatrice Cenci, immortalized by Shelley, killed her father, who had forced an incestuous relationship on her; there was no need of punishment from the point of view of individual prevention but general deterrence seemed to require punishment for parricide.

\section{Rehabilitation v. General Deterrence}

Finally, rehabilitation can be achieved often, and sometimes only, if there is no, or no severe, punishment, while punishment may be required from the point of view of general deterrence.

As these goals interfere with each other, the disposition of a case cannot always be equally satisfactory from all angles. Whenever 
our goals conflict, we have to weigh how much of each of these purposes can be achieved and how much sacrifice in terms of one goal is necessary for the partial realization of another one.

\section{ON the Possibility of a Trifocal Formulation of the Law}

At the present time, the general public is inclined to regard punishment as the only normal and adequate answer to a crime. Other dispositions of the offender such as, for example, a psychiatric commitment, are seen only in a negative light. In the eyes of the public the defendant who was found irresponsible got away with it-although commitment to a ward for the criminally insane is harder on the criminal than any except the extreme punishment.

It seems advisable, first of all, to reformulate our laws in such a way that they are no longer focused on punishment as the normal consequence of crime, with other dispositions taking their place as exceptions from the rule; and to allow for three alternate dispositions of the criminal, principally of equal penological rank, viz., punishment, custody and therapy (medical or educational). In such a system the court, after determining the facts of the case, would proceed to the consideration of the way in which the offender should best be dealt with from the point of view of the merits of the case, the requirements of public morality and public safety and the chances of the offender's rehabilitation; and would dispose of each case by punishment, custody or treatment, or by a combination of these, or by release, as seems best fitted to the total situation.

In this system, the psychiatrist could make a major contribution to the court's decision. He would not be forced to relinquish what insight psychiatry actually has gained into human behavior in favor of a testimony on issues of doubtful meaning and questionable relevance but could bring the resources of his knowledge to an evaluation of the consequences of the various rival dispositions in the case. Instead of the M'Naughten questions, the psychiatrist could be asked three questions which are equally meaningful to him and to an appropriate disposition of the case and which he frequently will be able to answer with reasonable estimates: is the lawbreaker dangerous, i.e., how likely is he to commit the same or another crime again; is he deterrable, is the motivation of his unlawful behavior such that anticipation of consequences can decisively influence his behavior; and is he treatable by medical or educational methods?

The psychiatrist could try to answer these questions without sacrificium intellectus and without fear that the implications of his 
words may carry a jury of laymen in a direction which does not seem warranted in terms of the actual scientific meaning of his words. His answers could substantially assist the court in arriving at a reasonable decision about the disposition of the case through punishment, custody, or treatment, as illustrated in the following scale:

\begin{tabular}{|c|c|c|}
\hline Symbol & Diagnostic Characterization & Disposition \\
\hline $1,1,1$ & $\begin{array}{l}\text { Dangerous } \\
\text { Deterrable } \\
\text { Treatable }\end{array}$ & $\begin{array}{l}\text { Punishment and } \\
\text { Treatment }\end{array}$ \\
\hline $1,1,2$ & $\begin{array}{l}\text { Dangerous } \\
\text { Deterrable } \\
\text { Not treatable }\end{array}$ & Punishment \\
\hline $1,2,1$ & $\begin{array}{l}\text { Dangerous } \\
\text { Not deterrable } \\
\text { Treatable }\end{array}$ & $\begin{array}{l}\text { Preventive Custody and } \\
\text { Treatment }\end{array}$ \\
\hline $1,2,2$ & $\begin{array}{l}\text { Dangerous } \\
\text { Nòt deterrable } \\
\text { Not treatable }\end{array}$ & Preventive Custody \\
\hline $2,1,1$ & $\begin{array}{l}\text { Not dangerous } \\
\text { Deterrable } \\
\text { Treatable }\end{array}$ & $\begin{array}{l}\text { Punishment with } \\
\text { Probationary Period and } \\
\text { Treatment }\end{array}$ \\
\hline $2,1,2$ & $\begin{array}{l}\text { Not dangerous } \\
\text { Deterrable } \\
\text { Not treatable }\end{array}$ & $\begin{array}{l}\text { Punishment, perhaps with } \\
\text { Probationary Period }\end{array}$ \\
\hline $2,2,1$ & $\begin{array}{l}\text { Not dangerous } \\
\text { Not deterrable } \\
\text { Treatable }\end{array}$ & Treatment \\
\hline $2,2,2$ & $\begin{array}{l}\text { Not dangerous } \\
\text { Not deterrable } \\
\text { Not treatable }\end{array}$ & Release \\
\hline
\end{tabular}

